\title{
III Electrochemical Effects at Surfactant-Platinum III Nanoparticle Interfaces Boost Catalytic Performance
}

\author{
Neyvis Almora-Barrios, ${ }^{[a]}$ Gianvito Vilé, $^{[b]}$ Miquel Garcia-Ratés, ${ }^{[a]}$ Javier Pérez-Ramírez, ${ }^{*[b]}$ and \\ Núria López ${ }^{*[a]}$
}

\begin{abstract}
Nanoparticles are applied in a variety of industrially relevant transformations as heterogeneous catalysts typically with the help of an external force (pressure, temperature, or voltage) to steer the chemistry. The modification of platinum nanoparticles by a phosphate-amino surfactant enables catalysis without external energy supply in the hydrogenation of nitrobenzene to aniline. This can be attributed to the complex surfactant/metal interface which is able to split hydrogen into protons and elec-
\end{abstract}

trons. The subsequent hydrogenation process mimics the electrochemical reduction described by Haber. The surfactant decorated Pt catalyst is two orders of magnitude more active than the state-of-the-art $\mathrm{Pb}$-poisoned $\mathrm{Pt}$ catalyst. Our study provides a new approach to understand the functionality of emerging catalytic systems and can be applied to design new materials with optimal interfaces.

\section{Introduction}

The conversion of a reactant into a valuable product often requires a catalyst and an additional force in the form of electrons (electrocatalysis), photons (photocatalysis), temperature, or pressure (traditional heterogeneous catalysis) to help the kinetics reaching a reasonable rate. Any of these stimuli imply that an external energy source needs to be applied. In the present work, we have identified that the modification of small platinum nanoparticles by phosphate-amino surfactants enables an intrinsic self-powered electrochemical nanoarchitecture with a pronounced catalytic promotion diminishing the external energy consumption.

Metal nanoparticles are well-established catalytic species. If their sizes are very small (typically below $2.5 \mathrm{~nm}$ ), ${ }_{1}^{[1]}$ their electronic structure can depart from that of the bulk material through electron confinement effects. According to Somorjai and co-workers, the altered electronic structure of very small Pt nanoparticles could be responsible for the enhanced catalyt-

[a] Dr. N. Almora-Barrios, Dr. M. Garcia-Ratés, Prof. N. López Institute of Chemical Research of Catalonia (ICIQ)

The Barcelona Institute of Science and Technology Av. Països Catalans 16

43007 Tarragona (Spain) E-mail:nlopez@iciq.es

[b] Dr. G. Vilé, Prof. J. Pérez-Ramírez

Institute for Chemical and Bioengineering

Department of Chemistry and Applied Biosciences ETH Zurich

Vladimir-Prelog-Weg 1

8093 Zurich (Switzerland)

E-mail:jpr@chem.ethz.ch

$\square$ Supporting information and the ORCID identification number(s) for the

(iD) aut author(s) of this article can be found under http://dx.doi.org/10.1002/ cctc. 201601134

III This manuscript is part of a Special Issue to celebrate the $50^{\text {th }}$ annual meeting of the German Catalysis Society. ic activity through the formation of hot $\mathrm{H}$ atoms. ${ }^{[2]}$ Adsorbates can modify the catalytic response of nanoparticles. Recent experiments for the direct peroxide synthesis on Pd nanoparticles, 0.7-7 $\mathrm{nm}$ average diameters, have found experimental indications of heterolytic $\mathrm{H}_{2}$ dissociation if acids and halides are present. $^{[3]}$

To better control their sizes and shapes, nanoparticles are often synthesized with the help of ligands. ${ }^{[4]}$ Ligand-modified nanoparticles can be synthesized with ionic liquids, ${ }^{[5]}$ polymers (e.g., poly(vinylpyrrolidone) or poly(vinyl alcohol) $)_{1}^{[6]}$ thiols, ${ }^{[7]}$ phosphines, ${ }^{[8]} \mathrm{N}$-basis, or surfactants. ${ }^{[9]}$ Thus, the variety of ligands that can be used is very large. It has been established that these ligand-modified nanoparticles exhibit properties that are different from those of conventional bare metals, owing to the complex and chemically rich inorganic/organic interface. ${ }^{[2 a, 10]}$ Ligands can 1) modify the ensemble size on the catalytically active surface, ${ }^{[7]} 2$ 2) reorient reactants or products, $^{[11]} 3$ ) change the acidic properties in the metal/surfactant/ water interface, ${ }^{[12]}$ and 4) alter the electronic structure of metal. ${ }^{[9]}$ The latter was described to be the main responsible for the selectivity of Pt nanowires $(\approx 1.1 \mathrm{~nm}$ in diameter) decorated with ethylenediamine in the partial hydrogenation of nitroarenes to hydroxylamine. ${ }^{[9]}$

Surfactants can also act as ligands but differently from polymers, phosphines, or N-basis, they are constituted by anionic and cationic units. This confers an extra degree of freedom (charge separation and electric field) ${ }^{[11 e]}$ in the materials design that might affect the activity and the selectivity of the samples if used as catalysts. The recent catalytic material developed by BASF featuring supported Pt (or Pd) nanoparticles decorated with the hexadecyl(2-hydroxyethyl) dimethylammonium dihydrogenphosphate (HHDMA) surfactant offers a unique platform to assess interface effects, also considering that these materials are the first to successfully reach the market and are currently 
used to catalyze the hydrogenation of alkynes and nitroarenes. ${ }^{[11]}$ By comparing this new catalyst with traditional materials in the hydrogenation of nitroarenes, we have observed a two-order-of-magnitude increase in the activity, which can only be attributed to the nature of the catalyst.

The surfactant-Pt-nanoparticle-mediated hydrogenation of nitrobenzene to aniline was studied through an approach combining experimental and theoretical methods. Special attention was paid to the description of the reaction network. Our results suggest that the combined effect of the nanoparticle curvature, the electron confinement, as well as the high density of electric field lines enable a catalytic process with no external energy supply.

\section{Results}

To investigate the role of the modification of $\mathrm{Pt}$ with the HHDMA surfactant, the Pt-HHDMA catalyst was compared with the Pb-poisoned Pt catalyst. ${ }^{[13]}$ The complete set of textural, compositional, and structural characterizations of the two materials is detailed both in the Experimental Section and in the Supporting Information (Section 1). The micrographs and particle size distribution of the hybrid Pt-HHDMA nanoparticles over the carbon support are shown in Figure $1 \mathrm{a}, \mathrm{b}$. The particles of this material are spherical and have an average diameter of approximately $1.7 \mathrm{~nm}$ (Figure $1 \mathrm{c}$ ).

From the combination of different experimental and computational characterization methods (Supporting Information), it appears that the Pt nanoparticles are decorated by the $\mathrm{H}_{2} \mathrm{PO}_{4}{ }_{-}^{-}$ group, and cationic, aliphatic, quaternary amino tails protect the structure (Figure $1 \mathrm{~d}, \mathrm{e})$. The Pb-poisoned Pt (Pt-Lindlar) catalyst, on the other hand, is characterized by spherical particles of approximately 7-8 $\mathrm{nm}$. This result is in agreement with results published in the literature. ${ }^{[11 e, f]}$ Since the Pt nanoparticle size can have a significant influence on the nitroarene hydrogenation performance, ${ }^{[14]}$ we opted to express the reaction rates as turnover frequency (moles of obtained product per moles of accessible metal and unit of time), using dispersion data obtained by $\mathrm{CO}$ chemisorption and transmission electron microscopy.

The catalysts were applied in the hydrogenation of nitrobenzene to aniline, an important reaction for the manufacture of polymers, agrochemicals, and pharmaceuticals. ${ }^{[15]}$ A continuous microreactor was used for the materials evaluation. The results of the catalytic tests (Figure 2) show that nitrobenzene hydrogenation on the Pt-HHDMA-decorated nanoparticles proceeds in a broad range of temperature and pressure (including $303 \mathrm{~K}$ and 1 bar), with a two orders of magnitude higher activity than that of the reference Pt-Lindlar. ${ }^{[13]}$ In Figure 2, the activity is shown per mole of accessible surface metal. Thus, the different reactivity of the two materials cannot be attributed to the different metal concentration and dispersion. Remarkably, an increase of the external forces over Pt-Lindlar of $70 \mathrm{~K}$ and 20 bar are not sufficient to attain the same activity of PtHHDMA. Hence, the difference between the two catalysts arises from the unique reactivity intrinsic to the complex interface of Pt-HHDMA. These results are not due to transient behavior and were confirmed for several hours of steady-state operation. Catalytic tests for the hydrogenation of chloronitrobenzene to chloronitroaniline have remarked the absence of (a)

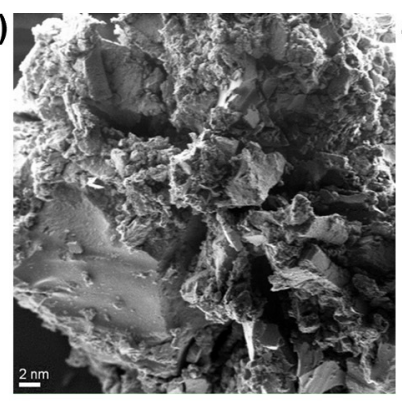

(d)

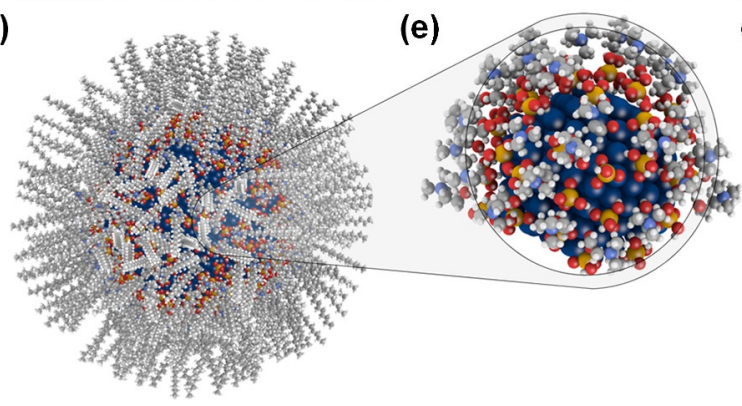

(b)
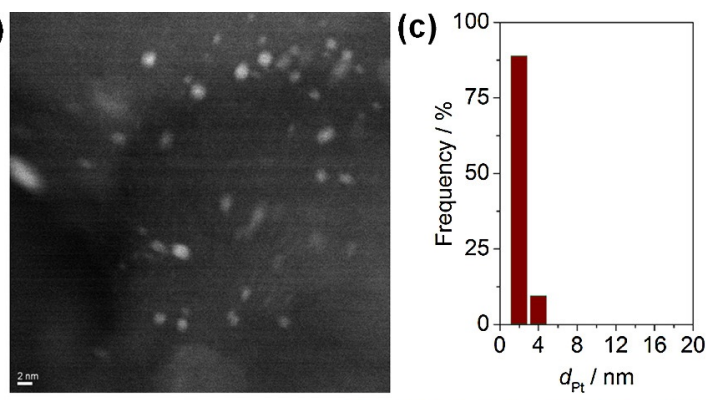

(f)

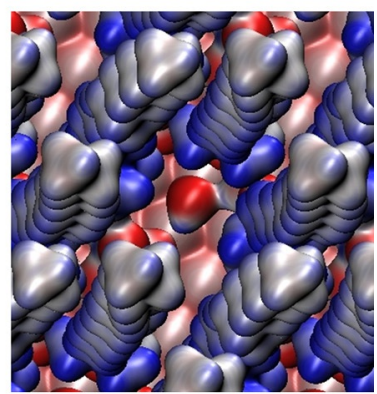

Figure 1. a) Scanning electron microscopy, b) high-angle annular dark-field scanning transmission electron microscopy, and c) metal size distribution of the PtHHDMA catalyst. Reproduced with permission from Ref. [11 f], Copyright 2015 American Chemical Society. d) Model representation of the structure of a single Pt nanoparticle with the full capping layer. e) Calculated structural model showing the preferential adsorption of phosphate groups on the surface of the $1.7 \mathrm{~nm}$ diameter Pt nanoparticle, and the external ammonia shell, $\mathrm{Pt}_{260}\left(\left[\mathrm{~N}\left(\mathrm{CH}_{3}\right)_{3} \mathrm{CH}_{2} \mathrm{OH}\right] \mathrm{H}_{2} \mathrm{PO}_{4}\right)_{57}$. Dark blue spheres represent metals, red oxygen, orange phosphorus, grey carbon, white hydrogen, and pale blue nitrogen. f) Molecular electrostatic potential mapped onto a 0.02 a.u. charge density isosurface for the surfactant channel. Red (blue) values account for attractive (repulsive) interactions, respectively. The darker the color the more intense the interaction with a positive charge. 


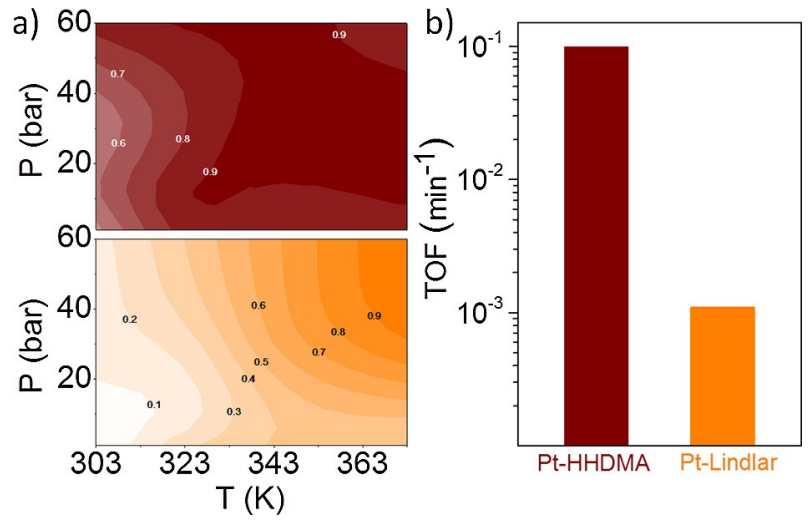

Figure 2. a) Conversion of nitrobenzene to aniline as a function of the hydrogen pressure and temperature over Pt-HHDMA (top) and Pt-Lindlar (Pt$\mathrm{Pb} / \mathrm{CaCO} 3$ ) (bottom). b) Turnover frequency (in logarithm scale) at $323 \mathrm{~K}$ temperature and 1 bar hydrogen pressure. The catalytic results are adapted with permission from Ref. [11f]. Copyright 2015 American Chemical Society.

any drop in nitroarene conversion and aniline selectivity at $303 \mathrm{~K}$ and $1 \mathrm{bar}$ for more than $10 \mathrm{~h}$ on stream; ;11f] besides, elemental analyses of the catalyst before and after hydrogenation have verified the absence of metal and HHDMA leaching.

From a mechanistic viewpoint, heterogeneously catalyzed hydrogenations on metals are often interpreted through the Horiuti-Polanyi mechanism, (HP), ${ }^{[16]}$ comprising homolytic dissociation of molecular hydrogen on the metal, adsorption of the organic reactant, and sequential hydrogen transfers to the adsorbed organic moiety to yield the desired product (Scheme 1). The formed product easily desorbs, and in the

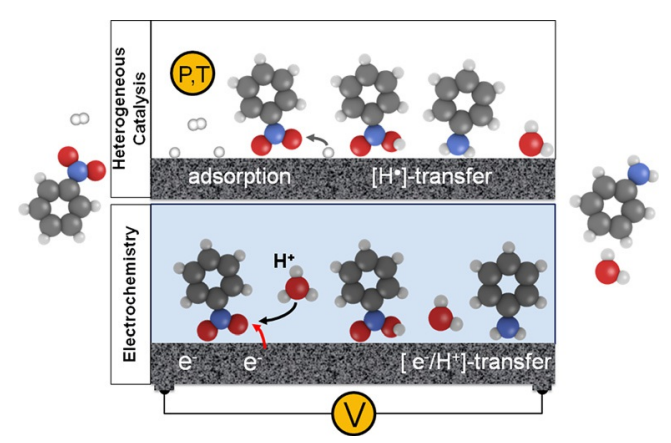

Scheme 1. Hydrogenation of nitrobenzene following the Horiuti-Polanyi ${ }^{[16]}$ and electrochemical (Haber) ${ }^{[17]}$ mechanisms displaying the external forces required.

case of the ligand-modified catalysts it desorbs through the ligand chains, which form channels of approximately $8 \AA$ in diameter, ${ }^{[11 e]}$ leaving the active site available for the next catalytic cycle. This mechanism holds for the semihydrogenation of alkynes on Pt, Pd, Pt-Lindlar, and Pd-HHDMA ${ }^{[11 e]}$ and for the hydrogenation of nitroarenes on Pt and Pt-Lindlar. ${ }^{[11 f]}$ In 1900, Haber showed that nitroarene hydrogenation ${ }^{[17]}$ in electrochemical environments occur through a different mechanism, which involves the sequential transfer of electrons supplied from the metal and protons available in the solution. This electron/proton transfer to the adsorbed organic moiety leads to the amine product on Pt electrodes at an external potential of $U=-0.51 \mathrm{eV}$ with respect to the reversible hydrogen electrode, RHE (Scheme 1).

For nitroarene hydrogenation, water is stoichiometrically generated in the catalytic cycle. However, on bare and alloyed Pt catalysts, water is weakly adsorbed $(-0.22 \mathrm{eV})$ and easily leaves the surface. On the hybrid Pt-HHDMA interface, the molecularly adsorbed water is further stabilized with an adsorption energy of $-1.20 \mathrm{eV}$, owing to electrostatic and $\mathrm{H}$-bond interactions. Notice that water is then not directly bonded to the Pt atoms but rather between hydrogenphosphate anions on the surface. The distance between the oxygen atom of the water molecule and the Pt surface atoms is approximately $3.37 \AA$ (see Figure S5). We have also studied an alternative model in which the water molecule is dissociated on the PtHHDMA, but the system is not as stable as that with the molecular adsorbed water.

The persistent presence of water molecule transforms the interface in a complex environment constituted by the metal phase, the electric field caused by the ions, and the ionic media (water-phosphates), leading to a network able to transport protons. As we will see in the following this has a large effect on the way molecular hydrogen can be activated.

Hydrogen activation was investigated through DFT calculations (RPBE-D2) ${ }^{[18]}$ on the Pt-HHDMA nanoparticles, $1.7 \mathrm{~nm}$ in diameter, modified by phosphate groups and water, and externally shielded by the quaternary ammonia surfactant tails (Figure 1 e) stoichiometry $\mathrm{Pt}_{260}\left(\left[\mathrm{~N}\left(\mathrm{CH}_{3}\right)_{3} \mathrm{CH}_{2} \mathrm{OH}\right] \mathrm{H}_{2} \mathrm{PO}_{4}\right)_{57}$ (half this model for the transition-state searches). Notice that the computational box volume was $40 \times 40 \times 40 \AA^{3}$, close to the limits of what is feasible with the present technical approach. Technical details are presented both in the Experimental Section and in the Supporting Information, Section 2.

On the Pt-HHDMA, molecular hydrogen can be activated in two different manners. The first one, remainder of the HP mechanism, follows the homolytic splitting of the $\mathrm{H}-\mathrm{H}$ bond, which leads to two final hydrogen atoms adsorbed on the metallic surface $\left(\mathrm{H}_{2}+2^{*} \rightarrow 2 \mathrm{H}^{*}\right.$, Figure 3). ${ }^{[16]}$ Alternatively, a heterolytic splitting of $\mathrm{H}_{2}$ can take place in the form of a dissociative Heyrovsky-like mechanism $\left(\mathrm{H}_{2}+{ }^{*} \rightarrow \mathrm{H}^{*}+\mathrm{H}^{+}+\mathrm{e}^{-}\right){ }_{1}^{[19]}$ which leads to a hydrogen on the surface, a proton at the polarizable interface formed by the surfactant $\mathrm{H}_{2} \mathrm{PO}_{4}^{-}$anionic head and the trapped water molecules, and an electron transferred to the metal (Figure 3). Both splitting pathways occur on the PtHHDMA surface without a barrier (Figure 3). The most stable final configuration is the formation of the proton-electron pair (by $-0.26 \mathrm{eV}$ ) (Figure 3, Table S4). Therefore, hydrogen activation on the Pt-HHDMA containing water results in the separation of hydrogen into electrons, which are stored in the metal phase, and protons, which are shared between the surfactant and adsorbed water.

\section{Discussion}

The electrochemical effects can be rationalized through a Born-Haber cycle. For the bare Pt surface, this cycle includes the following steps: 


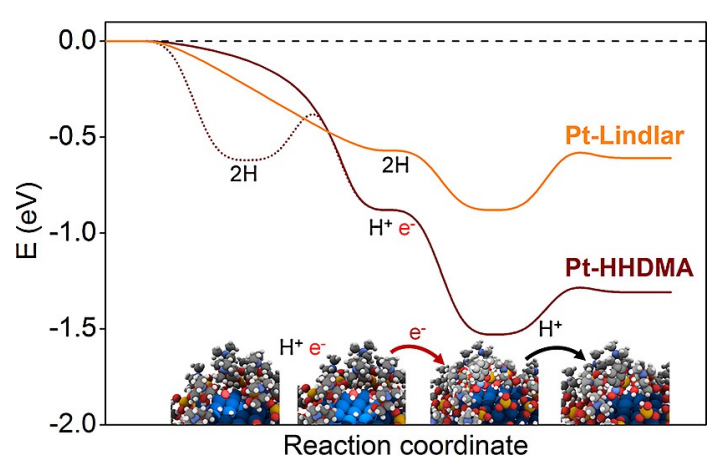

Figure 3. Reaction paths for the dissociation of $\mathrm{H}_{2}$ and the first hydrogenation step of nitrobenzene on Pt-Lindlar (orange) and coated HHDMA nanoparticle (wine), Pt-HHDMA with water for both the Langmuir-Hinshelwood (dotted) and the Heyrovsky (continuous line) processes. The insets represent the initial state structure, $\mathrm{H}^{+}-\mathrm{e}^{-}$separation, nitrobenzene adsorption, and proton transfer to the nitro group. Same color code as in Figure 1. The intermediates in the hydrogenation process are compared to pure Pt (see Supporting Information, Section 3.7.1 and 3.7.2). A movie with the full reaction network is uploaded as Supporting Information.

(1) Hydrogen dissociation:

$1 / 2 \mathrm{H}_{2} \rightarrow \mathrm{H} \quad \Delta E=2.3 \mathrm{eV}^{[20]}$

(2) Hydrogen charge separation:

$\mathrm{H} \rightarrow \mathrm{H}^{+}+\mathrm{e}^{-} \quad \mathrm{IP}=13.6 \mathrm{eV}^{[20]}$

(3) Proton solvation:

$\mathrm{H}^{+}+$water $\rightarrow\left(\mathrm{H}^{+}\right)_{\mathrm{w}} \quad E_{\text {solv }}=-10.9 \mathrm{eV}^{[21]}$

(4) Electron transfer to the metal:

$$
\mathrm{e}^{-}+\mathrm{Pt} \rightarrow\left(\mathrm{e}^{-}\right)_{\mathrm{Pt}} \quad \Phi(\mathrm{Pt})=5.9 \mathrm{eV}^{[20]}
$$

For which the reaction energies, $\Delta E$; ionization potential, IP; solvation energies, $E_{\text {solv }} ;$ and metal work function, $\Phi$, are defined. By combining steps (1)-(4), the total energy of the process is close to zero, in good agreement with previous results in the literature. ${ }^{[22]}$ For the Pt-HHDMA-water, however, the situation is different. The electron transfer to the surfactant-decorated metal is not effective because the electron affinity contribution (i.e., placing an extra electron in the nanoparticle) is not so favorable. Furthermore, owing to the presence of an extra term arising from the generated electric field, Equation (4) is replaced by:

(4') Electron transfer to the nanoparticle:

$$
\mathrm{e}^{-}+\mathrm{Pt}-\mathrm{HHDMA} \rightarrow\left(\mathrm{e}^{-}\right)_{\mathrm{Pt}-\mathrm{HHDMA}} \quad E A_{\mathrm{Pt}-\mathrm{HHDMA}}=-0.3 \mathrm{eV}
$$

$\left(4^{\prime \prime}\right)$ Electric field contribution:

$$
\left(\mathrm{e}^{-}\right)_{\text {Pt-HHDMA }}+\text { HHDMA } \quad E_{\text {Coulomb }} \cong-4 \mathrm{eV}
$$

For which $E A_{\mathrm{Pt}-\mathrm{HHDMA}}$ is the energy gained if an electron is included on the decorated nanoparticle and $E_{\text {Coulomb }}$ the electrostatic contribution between the electron in the metal and the surfactant. Therefore, the energy needed to split hydrogen into protons and electrons is compensated by the electron transfer to the metal and the electric field existing at the interface. The electronic state of the Pt-HHDMA catalyst with a water molecule after $\mathrm{e}^{-}-\mathrm{H}^{+}$charge separation can be described through a molecular electrostatic potential (MEP) map (see Figure $1 \mathrm{f}$ and Supporting Information Section 3.3). The
MEP map thus illustrates the potential "felt" by the molecule on its way to the active site on the surface. First, the aliphatic barrier created by the ligand needs to be crossed but then, once the surface is reached, there is a large difference if there is water (and thus protons) or not (and then only atomic $\mathrm{H}$ ). For the clean Pt-HHDMA system, the terminal P-O moieties and the quaternary ammonia head present red (attractive) and blue (repulsive) areas, respectively (Figure S6). If water and hydrogen are trapped, Pt-HHDMA-water- $\mathrm{H}^{+}$, the MEP is much more corrugated, with the electron basins (red) located at the metal surface (Figure $1 \mathrm{f}$ ).

The large charge density available on the metal of the PtHHDMA-water- $\mathrm{H}^{+}$catalyst enhances nitrobenzene adsorption, $-0.65 \mathrm{eV}$. The electron transfer towards the adsorbate results in the increase of the $\mathrm{N}-\mathrm{O}$ distance from 1.233 to $1.312 \AA$ and the molecular charge (Bader) of the molecule from -0.43 to $-0.77\left|\mathrm{e}^{-}\right|$. Thus, adsorption is much stronger than that for Pt-Lindlar $(-0.31 \mathrm{eV})$ surfaces (Table S5). From this point on, the reduction of nitrobenzene occurs as follows: electrons are collected from the charged nanoparticle and the protons are added to the oxygen atoms through the water/phosphate in terfacial network that acts as proton shuttle. The mechanism consists in electron-proton transfer (ECT) steps. ${ }^{[23]}$ The protons are transferred with very low energy barriers $(<0.3 \mathrm{eV}$ for the first step, Table S7). The process mimics the electrochemical processes in which electrons and protons are transferred sequentially. Recently, Zheng et al. ${ }^{[9]}$ found that Pt nanowires coated with ethylenediamine exhibit selectivity for the production of hydroxylamines. In our case, hydroxylamine is an intermediate species and aniline the only product (see Supporting Information Section 3.7.2 and Figure S9). One possible explanation is that in the presence of water/phosphate interfaces the reduction of hydroxylamine is enhanced because a protontransfer occurs to form water while the electron transfer occurs to form the $\mathrm{C}_{6} \mathrm{H}_{5}-\mathrm{NH}$ species.

The enhanced activity observed in Figure 2 can be traced back to the rates (Supporting Information Section 3.8). The first $\mathrm{H}$ transfer (either as $\mathrm{H}$ in $\mathrm{Pt}$-Lindlar or as $\mathrm{H}^{+}$in $\mathrm{Pt}-\mathrm{HHDMA}$ ) to adsorbed nitrobenzene controls the rate for hydrogenation [Eq. (1)]:

$r \approx k_{1 s \mathrm{t}} \theta_{\text {nitrobenzene }} \theta_{\mathrm{H}}$

where $k_{1 s t}$ is the kinetic coefficient for the first hydrogenation step, and $\theta$ the coverage of nitrobenzene and hydrogen, respectively. The hydrogen coverage is close to one as the adsorption barrier is below that of the reactants and not competitive and that of nitrobenzene can be expressed through a Langmuir isotherm. The adsorption of nitrobenzene is improved in the Pt-HHDMA surface and almost doubles that of the Pt-Lindlar system. On the other hand, the kinetic coefficient for the first hydrogen transfer, $k_{1 s t}$, is calculated to be approximately 300 times larger for the $\mathrm{H}^{+}$transfer in Pt-HHDMA than for hydrogen transfer on Pt-Lindlar. The combination of both terms results in the two orders of magnitude activity enhancement observed in Figure $2 \mathrm{~b}$. Notice that although water is adsorbed at the interface, it does not block potential active 


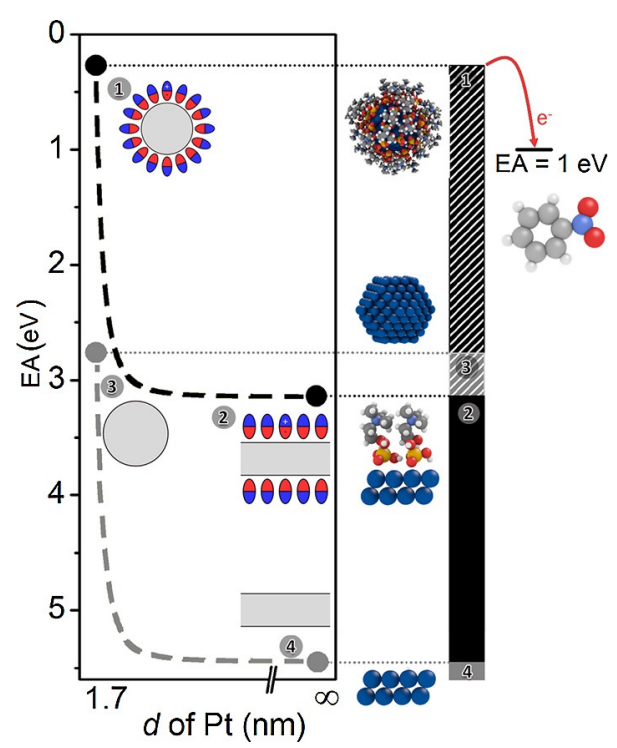

Figure 4. Confinement and electric field effects in the electron affinity of the different Pt structures. Left, electron affinities (circle) with respect to the nanoparticle size. On the right, the relative alignment of the electrons in the metal systems (column) are compared to the LUMO state of nitrobenzene (marked as $E A$ ) to highlight if electron transfer from the metal structures to the reactant is possible. 1) Coated HHDMA nanoparticle and 2) slab Pt structures, 3) bare nanoparticle and 4) slab configurations.

sites for nitrobenzene adsorption because it is located in the surroundings of the hydrogenphosphate anions.

To identify the origin of the electrochemical path in the PtHHDMA-water nanostructures, we have analyzed the chemical potential at which electrons are placed on the different Pt systems (Figure 4). The value of the electron affinity for the Pt-systems is crucial as the binding energy of nitrobenzene is dominated by the ability to inject electrons towards the LUMO (placed at $1 \mathrm{eV}$ ). On the $\mathrm{Pt}(111)$ surface, electrons are located at the electron affinity value, about $5.45 \mathrm{eV}$ (see Supporting Information, Table S3). Reducing the size of the metal nanoparticle to $1.7 \mathrm{~nm}$ leads to an electron affinity (as we are storing electrons in the nanoparticle this is the key parameter) of $2.76 \mathrm{eV}^{[24]}$ Instead, if the Pt(111) surface is coated with the surfactant, the electron affinity for the infinitely decorated surface, $3.14 \mathrm{eV}$, decreases to $0.27 \mathrm{eV}$ for the confined particle. Thus, close enough to the potential used by Haber, $0.51 \mathrm{eV}$. Only in the last case, electron injection towards nitrobenzene is possible. Notice that there is an apparent contradiction since hydrogen activation is rather exothermic (see Figure 3, the Heyrovsky processes in continuous line) but the electrons are placed at high chemical potential (Figure 4). However, the total system is stable thanks to the electrostatics between the different units.

The origin of this important shift in the chemical potential of the electrons can be traced back to the combined effect of: 1) electron confinement; 2) the high density of electric field lines generated by the surfactant; and 3) the large curvature of the small Pt nanoparticles, which is precisely the case of Pt synthesized by HHDMA (Figure $1 \mathrm{a}-\mathrm{c}$ ). This dependence is roughly $r^{-3}$ as for the interaction of a charge stored with di- poles (see Supporting Information Section 3.9). Compared to the experiments on clean nanoparticles, ${ }^{[2 b]}$ on which the activity amplification was a three-fold increase for nanoparticles with diameters between $4.5-1.7 \mathrm{~nm}$, the combined effect provides two orders enhancement.

\section{Conclusions}

We have found that a new catalytic formulation based on surfactant Pt nanoparticles behaves as an electrochemical system, splitting $\mathrm{H}_{2}$ into protons and electrons. The electrons stored in the nanoparticle are placed at high chemical potentials and favor nitrobenzene adsorption by charge transfer. Then electron-proton transfer occurs easily. The internal force generated at the interface of the hybrid system mimics the external potential employed in electrochemical environments without external stimuli. The performance of these hybrid nanoarchitectures breaks linear-scaling relationships ${ }^{[25]}$ and sets up a new, alternative mechanism that couples intrinsically generated electrochemical contributions and traditional heterogeneous catalysis, leading to a reduction in external energy consumption.

\section{Experimental Section}

\section{Experimental details}

Pt-HHDMA/C (0.8 wt.\% Pt; NanoSelect Pt 100, Strem Chemicals, ref: 78-1630), Pd-HHDMA/C (0.5 wt.\% Pd; NanoSelect LF 100, Strem Chemicals, ref: $46-1710$ ) and $\mathrm{Pd}-\mathrm{Pb} / \mathrm{CaCO}_{3}(5 \mathrm{wt} . \% \mathrm{Pd}$ and 3 wt.\% Pb; Alfa Aesar, ref: 043172) were used as received. Pt-Pb/ $\mathrm{CaCO}_{3}$ (5 wt.\% Pd and $1 \mathrm{wt} . \% \mathrm{~Pb}$ ) was prepared following a published method. ${ }^{[26]}$ The characterization of the catalysts is detailed in the Supporting Information, Section 1. The catalysts were evaluated in the three-phase hydrogenation of nitrobenzene, using a fully automated continuous-flow flooded-bed microreactor (ThalesNano $\mathrm{H}$-Cube Pro), ${ }^{[11, f]}$ at the following conditions: $W_{\text {cat }}=100 \mathrm{mg}$, $F_{\mathrm{G}}\left(\mathrm{H}_{2}\right)=18 \mathrm{~cm}^{3} \mathrm{~min}^{-1}$, and $F_{\mathrm{L}}($ nitroarene $+\mathrm{THF})=3 \mathrm{~cm}^{3} \mathrm{~min}^{-1}$.

\section{Computational details}

A combination of computational techniques, ab initio Molecular Dynamics, and quantum-mechanical methods based on the density functional theory (DFT) were used within the Vienna ab initio simulation package (VASP). ${ }^{[17 a, b]}$ Total energies and electron densities were computed with Perdew-Burke-Ernzerhof (RPBE) functional ${ }^{[17 c]}$ complemented by the dispersion D2 term as presented by Grim$m e^{[17 \mathrm{~d}]}$ with our refitted values for the metals. ${ }^{[17 \mathrm{e}]}$ The projected augmented wave (PAW) method was adopted to represent core electrons. ${ }^{[27]}$ The kinetic energy cutoff for the plane-wave basis set expansion was set to $450 \mathrm{eV}$. A $3 \times 3 \times 1 k$-point mesh for the slab models, and a $\Gamma$-point centered mesh for cluster models were used to sample the reciprocal space. ${ }^{[28]}$

With regard to the metal surfaces, we have adopted different strategies. The slab model represents close-packed (111) face of metals, containing five atomic layers and a $p(4 \times 4)$ supercell with a vacuum gap of approximately $20 \AA$. The three topmost layers on one side of the slab were optimized and dipole corrections were used in the $z$-direction. For Pt-Lindlar, the continuum slab model was employed because the average diameter of the $\mathrm{Pt}-\mathrm{Pb}$ nano- 
particles in the system was around $8 \mathrm{~nm}$. Four platinum atoms in the first layer of $\mathrm{Pt}(111)$ were substituted with lead with a $0.25 \mathrm{ML}$ coverage $\left(\mathrm{Pt}_{3} \mathrm{~Pb}(111)\right)$. The $\mathrm{Pt}$ nanoparticle (PtNP) is a cuboctahedron containing $260 \mathrm{Pt}$ atoms with a diameter of $1.7 \mathrm{~nm}$ (see Figure S3). For the calculation of the PtNP properties, the system was modeled as a cubic box with dimensions of $30 \times 30 \times 30 \AA^{3}$ and monopole corrections were used for charged systems. A summary of the details for the calculation of electron affinity (EA) for all the simulated systems is reported in Supporting Information, Table S2.

PtNP and $\mathrm{Pt}(111)$ models were capped with a number of $\left[\mathrm{N}\left(\mathrm{CH}_{3}\right)_{3} \mathrm{CH}_{2} \mathrm{OH}\right] \mathrm{H}_{2} \mathrm{PO}_{4}$ molecules in agreement with the experimental concentrations. The $\mathrm{Pt}_{260}$ cluster with the 57 $\left(\left[\mathrm{N}\left(\mathrm{CH}_{3}\right)_{3} \mathrm{CH}_{2} \mathrm{OH}\right] \mathrm{H}_{2} \mathrm{PO}_{4}\right)$ adsorbates was pre-equilibrated through ab initio Molecular Dynamics at $303 \mathrm{~K}$ for 1 ps in a cubic simulation cell with a volume of $40 \times 40 \times 40 \AA^{3}$. The simulation was performed in the NVT ensemble using VASP code. The Nosé-Hoover thermostat was used to control the temperature with a time step of $1 \mathrm{fs}$ and a cutoff energy of $450 \mathrm{eV}$. The configuration was equilibrated until the total energy of the system fluctuated around a value with an amplitude of $0.1 \mathrm{eV}$. These structures; PtNP$\left[\mathrm{N}\left(\mathrm{CH}_{3}\right)_{3} \mathrm{CH}_{2} \mathrm{OH}\right] \mathrm{H}_{2} \mathrm{PO}_{4}$, and $\mathrm{Pt}(111)-\left[\mathrm{N}\left(\mathrm{CH}_{3}\right)_{3} \mathrm{CH}_{2} \mathrm{OH}\right] \mathrm{H}_{2} \mathrm{PO}_{4}$, were then taken as initial states for the study of adsorption and reaction. For the reaction mechanism, a half of this nanoparticle (stoichiometry $\left.\mathrm{Pt}_{178}\right)$ and 32 units of $\left[\mathrm{N}\left(\mathrm{CH}_{3}\right)_{3} \mathrm{CH}_{2} \mathrm{OH} \mathrm{H}_{2} \mathrm{PO}_{4}\right.$ were taken to reduce the computational cost with a box volume of $40 \times 30 \times$ $40 \AA^{3}$. The climbing image nudged elastic band (Cl-NEB) algorithm ${ }^{[29]}$ was used to find the transition states of the elementary steps involved in the dissociation of $\mathrm{H}_{2}$ and the first $\mathrm{H}$ transfer to the nitrobenzene. Finally, the $\mathrm{MEP}^{[30]}$ has been calculated with VASP and mapped onto a charge density isosurface using the Visual Molecular Dynamics v.1.8.7 (VMD) software. ${ }^{[31]}$ Our coordinates of all structures are already available through our repository platform ioChem-BD.org ${ }^{[32]}$ see DOI: 10.19061/iochem-bd-1-9.

\section{Acknowledgements}

Support from BSC-RES, ICIQ Foundation, MINECO (CTQ201568770-R and "Ayuda formación Post-doctoral" Fellowship (N.A.B.)), and ETH Zurich are acknowledged.

Keywords: density functional calculations - hydrogenation interfaces $\cdot$ platinum $\cdot$ surfactants

[1] a) L. Li, F. Abild-Pedersen, J. Greeley, J. K. Nørskov, J. Phys. Chem. Lett. 2015, 6, 3797-3801; b) L. Li, A. H. Larsen, N. A. Romero, V. A. Morozov, C. Glinsvad, F. Abild-Pedersen, J. Greeley, K. W. Jacobsen, J. K. Norskov, J. Phys. Chem. Lett. 2013, 4, 222-226.

[2] a) C. A. Witham, W. Huang, C.-K. Tsung, J. N. Kuhn, G. A. Somorjai, F. D. Toste, Nat. Chem. 2010, 2, 36-41; b) H. Lee, I. I. Nedrygailov, C. Lee, G. A. Somorjai, J. Y. Park, Angew. Chem. Int. Ed. 2015, 54, 2340-2344 Angew. Chem. 2015, 127, 2370-2374; c) J. Y. Park, H. Lee, J. R. Renzas, Y. Zhang, G. A. Somorjai, Nano Lett. 2008, 8, 2388-2392.

[3] N. M. Wilson, D. W. Flaherty, J. Am. Chem. Soc. 2016, 138, 574-586.

[4] N. Almora-Barrios, G. Novell-Leruth, P. Whiting, L. M. Liz-Marzán, N. López, Nano Lett. 2014, 14, $871-875$.

[5] a) S. W. Boettcher, S. A. Berg, M. Schierhorn, N. C. Strandwitz, M. C. Lonergan, G. D. Stucky, Nano Lett. 2008, 8, 3404-3408; b) V. Cimpeanu, M. Kočevar, V. I. Parvulescu, W. Leitner, Angew. Chem. Int. Ed. 2009, 48, 1085-1088; Angew. Chem. 2009, 121, 1105-1108.

[6] F. Cárdenas-Lizana, C. Berguerand, I. Yuranov, L. Kiwi-Minsker, J. Catal. 2013, 301, 103-111.

[7] a) S. T. Marshall, M. O'Brien, B. Oetter, A. Corpuz, R. M. Richards, D. K. Schwartz, J. W. Medlin, Nat. Mater. 2010, 9, 853-858; b) D. Albani, G.
Vilé, S. Mitchell, P. T. Witte, N. Almora-Barrios, R. Verel, N. López, J. PérezRamírez, Catal. Sci. Technol. 2016, 6, 1621-1631.

[8] I. Cano, M. A. Huertos, A. M. Chapman, G. Buntkowsky, T. Gutmann, P. B. Groszewicz, P. W. N. M. van Leeuwen, J. Am. Chem. Soc. 2015, 137, $7718-7727$.

[9] G. Chen, C. Xu, X. Huang, J. Ye, L. Gu, G. Li, Z. Tang, B. Wu, H. Yang, Z. Zhao, Z. Zhou, G. Fu, N. Zheng, Nat. Mater. 2016, 15, 564-569.

[10] a) C. Wang, R. Ciganda, L. Salmon, D. Gregurec, J. Irigoyen, S. Moya, J. Ruiz, D. Astruc, Angew. Chem. Int. Ed. 2016, 55, 3091-3095; Angew. Chem. 2016, 128, 3143-3147; b) P. T. Witte, M. De Groen, R. M. De Rooij, P. Bakermans, H. G. Donkervoort, P. H. Berben, J. W. Geus in Studies in Surf. Sci. and Catalysis, Vol. 175, (Eds.: E. M. Gaigneaux, M. Devillers, S. Hermans, P. A. Jacobs, J. A. Martens, P. Ruiz), Elsevier, Amsterdam, 2010, pp. $135-143$.

[11] a) P. T. Witte, S. Boland, F. Kirby, R. vanMaanen, B. F. Bleeker, D. A. M. deWinter, J. A. Post, J.W. Geus, P. H. Berben, ChemCatChem 2013, 5, $582-587$; b) P. T. Witte, P. H. Berben, S. Boland, E. H. Boymans, D. Vogt, J. W. Geus, J. G. Donkervoort, Top. Catal. 2012, 55, 505-511; c) S. W. T. Price, K. Geraki, K. Ignatyev, P. T. Witte, A. M. Beale, J. F. W. Mosselmans, Angew. Chem. Int. Ed. 2015, 54, 9886-9889; Angew. Chem. 2015, 127 10024-10027; d) G. Vilé, D. Albani, N. Almora-Barrios, N. López, J. PérezRamírez, ChemCatChem 2016, 8, 21-33; e) G. Vilé, N. Almora-Barrios, S. Mitchell, N. López, J. Pérez-Ramírez, Chem. Eur. J. 2014, 20, 5926-5937; f) G. Vilé, N. Almora-Barrios, N. López, J. Pérez-Ramírez, ACS Catal. 2015, 5, 3767-3778.

[12] D. Albani, Q. Li, G. Vilé, S. Mitchell, N. Almora-Barrios, P. T. Witte, N. López, J. Pérez-Ramírez, Green Chem. 2017, DOI:10.1039/C6GC02586B.

[13] H. Lindlar, Helv. Chim. Acta 1952, 35, 446-450.

[14] F. Zhao, Y. Ikushima, M. Arai, J. Catal. 2004, 224, 479-483.

[15] a) A. Corma, P. Serna, Science 2006, 313, 332-334; b) H.-U. Blaser, H. Steiner, M. Studer, ChemCatChem 2009, 1, 210-221.

[16] I. Horiuti, M. Polanyi, Trans. Faraday Soc. 1934, 30, 1164- 1172.

[17] F. Haber, Angew. Chem. 1900, 13, 433-439.

[18] a) G. Kresse, J. Furthmüller, Phys. Rev. B 1996, 54, 11169-11186; b) G. Kresse, J. Furthmüller, Comput. Mater. Sci. 1996, 6, 15-50; c) B. Hammer, L. B. Hansen, J. K. Nørskov, Phys. Rev. B 1999, 59, 7413-7421; d) S Grimme, J. Comput. Chem. 2006, 27, 1787-1799; e) N. Almora-Barrios, G. Carchini, P. Blonski, N. Lopez, J. Chem. Theory Comput. 2014, 10, 5002-5009.

[19] J. Heyrovský, Recl. Trav. Chim. Pays-Bas 1927, 46, 582- 585.

[20] a) J. A. Kerr in CRC Handbook of Chemistry and Physics, 84th ed. (Ed: D. R. Lide), CRC, Boca Raton, 2003, pp. 9-55; b) T. M. Miller, Ibidem, pp. $10-$ 178 ; c) J. S. Miller, Ibidem, pp. 12-130.

[21] Y. Marcus, J. Chem. Soc. Faraday Trans. 1991, 87, 2995-2999.

[22] J. K. Nørskov, T. Bligaard, A. Logadottir, J. R. Kitchin, J. G. Chen, S. Pandelov, U. Stimming, J. Electrochem. Soc. 2005, 152, J23-J26.

[23] a) M. H. V. Huynh, T. J. Meyer, Chem. Rev. 2007, 107, 5004-5064; b) M. T. M. Koper, Chem. Sci. 2013, 4, 2710-2723.

[24] Y. Zhang, O. Pluchery, L. Caillard, A.-F. Lamic-Humblot, S. Casale, Y. J. Chabal, M. Salmeron, Nano Lett. 2015, 15, 51-55.

[25] J. K. Norskov, T. Bligaard, J. Rossmeisl, C. H. Christensen, Nat. Chem. 2009, 1, 37-46.

[26] U. B. Siegrist, P. Baumeister, H. U. Blaser, M. Studer in Catalysis of Organic Reactions, Vol. 75 (Ed.: F. E. Herkes), Marcel Dekker, New York, 1998, pp. $207-219$.

[27] G. Kresse, D. Joubert, Phys. Rev. B 1999, 59, 1758-1775.

[28] H. J. Monkhorst, J. D. Pack, Phys. Rev. B 1976, 13, 5188-5192.

[29] G. Henkelman, B. P. Uberuaga, H. Jónsson, J. Chem. Phys. 2000, 113, $9901-9904$.

[30] M. Orozco, F. J. Luque in Molecular Electrostatic Potentials: Concepts and Applications, Vol. 3 (Eds: J. S. Murray, K. Sen), Elsevier, Amsterdam, 1996, pp. $181-218$

[31] W. Humphrey, A. Dalke, K. Schulten, J. Mol. Graphics 1996, 14, 33-38.

[32] M. Álvarez-Moreno, C. de Graaf, N. López, F. Maseras, J. M. Poblet, C. Bo, J. Chem. Inf. Model. 2015, 55, 95-103.

Manuscript received: September 11, 2016

Accepted Article published: October 4, 2016

Final Article published: November 29, 2016 